Marquette University

e-Publications@Marquette

College of Nursing Faculty Research and

Publications

Nursing, College of

$10-1-2015$

\title{
Conducting Research with Community Groups
}

Mary Molewyk Doornbos

Calvin College

Adejoke Ayoola

Calvin College

Gail Landheer Zandee

Marquette University

Robert V. Topp

Marquette University, robert.topp@marquette.edu

Accepted version. Western Journal of Nursing Research, Vol 37, No. 10 (October 2015): 1323-1339. DOI. (C) 2015 SAGE Publications. Used with permission. 
NOT THE PUBLISHED VERSION; this is the author's final, peer-reviewed manuscript. The published version may be accessed by following the link in the citation at the bottom of the page.

\title{
Conducting Research with Community Groups
}

\author{
Mary Molewyk Doornbos \\ Calvin College, \\ Grand Rapids, MI \\ Adejoke Ayoola \\ Calvin College, \\ Grand Rapids, MI \\ Robert Topp \\ College of Nursing, Marquette University \\ Milwaukee, WI \\ Gail Landheer Zandee \\ College of Nursing, Marquette University \\ Milwaukee, WI
}

\begin{abstract}
Nurse scientists are increasingly recognizing the necessity of conducting research with community groups to effectively address complex health problems and successfully translate scientific advancements into the community. While several barriers to conducting research with community groups exist, community based participatory research (CBPR) has the potential to mitigate these barriers. CBPR has been employed in programs of research that respond in culturally sensitive ways to identify community needs and thereby address current health disparities. This manuscript presents case studies that demonstrate how CBPR principles guided the development of: (a) a healthy body weight program for urban, underserved African-American women, (b) a reproductive health educational intervention

Western Journal of Nursing Research, Vol 37, No. 10 (October 2015): pg. 1323-1339. DOI. This article is (C) SAGE Publications and permission has been granted for this version to appear in e-Publications@Marquette. SAGE Publications does not grant permission for this article to be further copied/distributed or hosted elsewhere without the express permission from SAGE Publications.
\end{abstract}


for urban, low-income, underserved, ethnically diverse women, and (c) a pilot anxiety/depression intervention for urban, low-income, underserved, ethnically diverse women. These case studies illustrate the potential of CBPR as an orientation to research that can be employed effectively in non-research intensive academic environments.

Keywords: Community-based participatory research, community, women

There is an increasing awareness of the necessity of conducting healthcare research with community groups. Collaboration between academia and communities is essential to effectively address multifaceted health problems and successfully translate scientific advancements into the community. While several barriers to conducting research with community groups exist, community based participatory research (CBPR) has the potential to mitigate these barriers. This paper will demonstrate that non-research intensive academic settings, with limited research funding and predominatelyundergraduate populations, can employ CBPR to address complex health problems and make significant contributions to the science of our discipline.

\section{An Emerging Emphasis on Conducting Research with Community Groups}

There is an emerging emphasis on involving community groups at every stage of the research process to effect social change and address existing health disparities in the United States (Israel, Schulz, Parker, \& Becker, 2001; Minkler, 2011; Wallerstein \& Duran, 2010). The existing health inequities, especially among ethnic minorities and underserved populations, warrant concerted effort from nurses and other health professionals to improve health outcomes. Ethnic minority women who are obese, have gestational diabetes, or carry a family history of diabetes are affected more frequently by chronic illnesses such as hypertension and diabetes (Centers for Disease Control and Prevention, 2014). Many minority women struggle with mental illnesses such as depression (González, Tarraf, Whitfield, \& Vega, 2010; McGuire \& Miranda, 2008) and are at increased risk of unintended pregnancies (Finer \& Henshaw, 2006; Finer \& Zolna, 2011). Racial and ethnic minorities continue to experience a disproportionately higher rate of maternal and infant morbidity and mortality (Anachebe, 2006; Hauck, Tanabe, \& Moon, 2011; Mathews \& 
MacDorman, 2013; Office of Minority Health \& Health Disparities [OMHD], 2009; Tucker, Berg, Callaghan, \& Hsia, 2007). Poor access to care or inadequate use of available services such as prenatal care services and mental health services also complicate these disparities (OMHD, 2009; The Henry J. Kaiser Family Foundation, 2009).

Most health problems have multifaceted causation. Traditional methods of scientific inquiry that strive to minimize "confounding" factors in favor of testing the impact of a single, theoretically derived intervention on a single outcome are not well suited to complex community based health issues. Traditional research approaches also tend to separate researchers from the community where the problems exist. This approach fails to incorporate the impact and interaction of environmental, socioeconomic, and political factors that significantly contribute to health issues. In short, traditional research approaches have failed to solve complex health problems such as obesity, depression/anxiety, and unintended pregnancy. Investigator-perceived health care needs and researcher-generated resources may not result in viable solutions or necessary social change. Rather, when community members identify both their problems and the solutions, meaningful change can occur. Therefore, it is essential to collaborate with community groups in designing research that will effectively address current health disparities.

\section{Barriers to Conducting Research with Community Groups}

While the necessity of conducting research with community groups is apparent, several barriers commonly exist. First, researchers may constitute "outsiders" who are not trusted by the community (George, Duran, \& Norris, 2014). The sources of mistrust likely relate to a perception that researchers wish to study the community without attempts to enhance the effectiveness of existing community organizations as well as to potential differences in language, timelines, focus, objectives, and outcomes. Correspondingly, Ford et al. (2013) found that African Americans identified a need for research teams to recognize past research abuses and enhance community trust in order to increase enrollment of persons of color in studies. The development of the requisite trust occurs over time and must couple with 
persistence, consistency, and long-term commitment. Additionally, mistrust may align with perceived power issues, as researchers may not engage in necessary power sharing with community groups. Community groups fear exploitative power issues and perceive an inherent power differential between academic and community sectors (George et al., 2014; Rugkasa \& Canvin, 2011). Often community groups require evidence that the research will benefit rather than harm them and desire reciprocal relationships with the research team or academic unit (George, et al., 2014; Rugkasa \& Canvin, 2011). Without these, gatekeepers to communities may block the research. Further, researchers often do not align their studies with problems that are important to the community but instead advance their own agendas. Researchers must be willing to explore priorities identified by the community so that the community realizes timely benefits from the project. Kneipp, Lutz and Means (2009) found that the most compelling reason for low-income women to participate in research was that the researchers recognized an unmet need in their community. Finally, at times researchers have developed interventions that are not relevant, feasible, or acceptable to community members. Studies may fail to recognize or minimize cultural differences, transportation challenges, socioeconomic barriers, or the issues associated with immigration status. Ford et al. (2013) emphasized this point by suggesting tailored, barrier-focused interventions to improve participation among diverse ethnic groups in clinical trials.

\section{Community Based Participatory Research (CBPR) as a Response to Barriers}

CBPR is a "transformative research paradigm that bridges the gap between science and practice through community engagement and social action to increase health equity" (Wallerstein \& Duran, 2010, S40). It represents an opportunity to unite the interests of health professionals, academics, and communities in providing underserved communities a voice in research and increasing the likelihood of an intervention's success (Wallerstein \& Duran, 2010). CBPR has been described as a research partnership that involves community members and academic researchers as equal partners in all aspects of the research process and empowers all partners to contribute expertise, share decision-making, and assume ownership

Western Journal of Nursing Research, Vol 37, No. 10 (October 2015): pg. 1323-1339. DOI. This article is @ SAGE Publications and permission has been granted for this version to appear in e-Publications@Marquette. SAGE Publications does not grant permission for this article to be further copied/distributed or hosted elsewhere without the express permission from SAGE Publications. 
(Israel, Schulz, Parker, \& Becker, 1998; Israel et al., 2008). As such, CBPR has the potential to reduce health disparities by identifying the unique needs of minority communities and addressing health policy questions at the local level in ways that are likely impossible at the national level (O'Brien \& Whitaker, 2011). Therefore, in the last decade, CBPR has emerged as a model for translating scientific evidence into practice through community engagement and social action to reduce health disparities (Wallerstein \& Duran, 2010). There are nine components of CBPR including: 1) recognizing community as a unit of identity; 2 ) building on strengths and resources within the community; 3) facilitating collaborative, equitable involvement of all partners in all phases of the research; 4) integrating knowledge and action for mutual benefit of all partners; 5 ) promoting a co-learning and empowering process that attends to social inequalities; 6 ) involving a cyclical and iterative process; 7) addressing health from both positive and ecological perspectives; 8 ) disseminating findings and knowledge gained to all partners; and 9) involving a long-term commitment by all partners (Israel, et al., 1998; Israel, et al., 2001; Israel et al., 2008). Each of these elements can reduce the barriers associated with research with communities and result in multiple benefits to science and to community residents.

\section{CBPR Case Studies}

The following case studies demonstrate implementation of CBPR in academic settings with limited external research funding. The case studies represent two types of non-research intensive institutions-a faith based regional university and a private, religiously affiliated liberal arts college. Given this focus on conducting research in nonresearch intensive environments, many of the specific details pertaining to the research methods were not included.

\section{Maintaining Healthy Body Weight among Underserved African-American Women}

Through a transformational Catholic, Jesuit education, Marquette University College of Nursing (MUCN) prepares nurse leaders to promote health, healing, and social justice for all people through clinical practice and development of nursing knowledge. To 
enact this mission, the MUCN operates a nurse-run clinic for women and children in the basement of a local church located in an underserved, economically impoverished, primarily African-American neighborhood adjacent to the university.

This case study will describe how one community-academic partnership employed CBPR principles, considered sociocultural factors to refine the definition of overweight and obesity, and developed an intervention program for urban, underserved African-American women. Constituents of this partnership included academicians, clinicians, persons attending a community health clinic, and members of the church where the community health clinic was located. Two local programs funded this partnership. The project team incorporated CBPR principles throughout all phases of the research process to increase the probability of developing an effective, sustainable program acceptable to the targeted community. This decision required members of the target community to be involved in all phases of the research process including defining the problem, designing and delivering the intervention, and identifying outcome variables. This decision to incorporate CBPR principles into the research process helped build trust and partnership with the community while developing an intervention relevant to the problems identified by the community.

A preliminary study formed the basis for this project. Campbell et al. (2013) identified that approximately $80 \%$ of the AfricanAmerican women attending the community health clinic were overweight or obese and that this excessive body weight predicted treatment for a greater number of chronic conditions and prescriptions for more medications. In an attempt to determine if this data constituted a perceived problem for the community, the project team conducted focus groups with members of the targeted community. The participants redefined this problem of excessive body weight as a lack of access to resources that would encourage the women to engage in healthy eating and increased physical activity. These focus groups revealed that excessive body weight, defined by the community as "big," "thick" or "curvy", was a desirable attribute that the women did not wish to change. In fact, the terms "obesity" or "overweight" were rarely if ever mentioned by members of the focus groups. Thus, community members were equal partners with the academics in 
defining the problem as a lack of access to nutritional and physical activity resources that would contribute to a healthy body weight. This process redirected the research team to an articulation of a problem that the community participated in defining and invested in addressing.

The research team also employed CBPR principles in establishing a Project Advisory Board (PAB) comprised of equal numbers of female members of the community and members of the research team. The research team formed the PAB immediately following notification of funding by approaching residents of the target community who were members of the church or attended the community health clinic, explaining the purpose of the project, and asking if they would volunteer to advise the project team via membership on the PAB. Prior to implementation, the PAB approved the recruitment techniques, components of the intervention, selection of outcome variables, and approaches to human subjects' challenges. For example, recruitment occurred via word of mouth and fliers placed in the community health clinic and the church. Further, the PAB advised the project team they could build trust with the targeted community by employing members of the community as community health workers (CHWs) to assist in the collection of data and administration of the intervention. The PAB's recommendation to develop social support groups to administer the intervention was particularly effective since social support groups were an established approach that community members used for recognizing each other's personal accomplishments. These social support groups provided affirmation and accountability for members as they progressed toward improving their nutrition and increasing their physical activity. For example, members stated to one another "I saw you walking the other day-good job!" or "We missed you at the [social support] group last week." Thus, members of the community took responsibility for developing and maintaining adherence to the interventions administered through social support groups. This approach enabled delivery of components of the intervention within an established target community social structure.

Incorporating CBPR principles into a program of research also involves overcoming a number of barriers including maintaining scientific rigor while being considerate of sociocultural factors within

Western Journal of Nursing Research, Vol 37, No. 10 (October 2015): pg. 1323-1339. DOI. This article is (C) SAGE Publications and permission has been granted for this version to appear in e-Publications@Marquette. SAGE Publications does not grant permission for this article to be further copied/distributed or hosted elsewhere without the express permission from SAGE Publications. 
the community. For example, the PAB indicated that the target community would be hesitant to volunteer for a project that involved the venipuncture as originally suggested by the research team. Alternatively, the PAB advised the research team that the women would be amenable to data collection by a finger stick. Additionally, community members on the PAB informed the research team that assessing female participants' body composition through partial disrobing and use of skin fold calibers would be objectionable. The PAB indicated that many participants would refuse this assessment and/or be embarrassed during this form of data collection. The use of a handheld bioelectrical impedance meter that did not require the women to disrobe to measure body composition constituted an agreeable compromise for both the research team and the community members. Therefore, employing components of CBPR allowed the target community to collaborate as an equal partner with the research team in negotiating mutually agreeable compromises in the research methodology that contributed to the overall success of the project.

This CBPR project included a number of strengths and limitations. A strength of this project was that, via participation in the PAB, members of the community contributed equally with the project team. This community involvement likely averted a number of difficulties in addressing the problem. The community members were instrumental in redefining the problem, developing an intervention that took advantage of an established community social structure, and identifying feasible outcomes for assessment. This CBPR project also included a number of limitations. First, it would have been beneficial to involve the PAB even earlier in the research process. Second, sustaining the intervention beyond the extramural funding period is a challenge since most third party providers do not reimburse for nondisease focused services provided by non-health professionals. With preliminary data indicating the efficacy of this CBPR project, the church and community health clinic are exploring other sources of funding to maintain it. A third limitation was that the Institutional Review Board required human subjects research training for the community members if they were obtaining informed consent, collecting data, or administering the intervention. In addition, academic members of the project team had to be considerate of the limited scientific training of the community members. Without formal scientific training, community members did not recognize the

Western Journal of Nursing Research, Vol 37, No. 10 (October 2015): pg. 1323-1339. DOI. This article is @ SAGE Publications and permission has been granted for this version to appear in e-Publications@Marquette. SAGE Publications does not grant permission for this article to be further copied/distributed or hosted elsewhere without the express permission from SAGE Publications. 
importance of scientific rigor that may have threatened the validity of the project. Finally, community members experienced competing priorities in their personal lives that hindered their involvement with the project including changes in residence and phone numbers, alterations in employment status, family commitments, and transportation challenges.

\section{Health Promotion Programs for Urban, Low- Income, Ethnically Diverse Women}

The Calvin College Department of Nursing (CCDON) is located in a private, religiously affiliated, liberal arts college of 4,000 students. Consistent with the mission of its parent institution, the department forged partnerships with four urban, underserved, and impoverished neighborhoods that are populated with predominately Black, Hispanic, White, and homeless persons respectively. These neighborhood partnerships range in age from four to 12 years. The department's initial work with these neighborhoods involved nine focus groups and 449 door-to-door surveys intended to map out strategic health plans that captured the perceived strengths as well as the health related concerns of the residents (Zandee, 2012). Following data collection, residents participated in interpreting results, setting priorities, and envisioning how health issues might be addressed. The strategic health plan process repeats every seven years such that outcomes of resident-driven solutions are documented and new priorities set. The department designated two unique faculty positions to manage its neighborhood partnerships-a community partnership coordinator (CPC) and a neighborhood coordinator (Feenstra, Gordon, Hansen \& Zandee, 2006). The CPC functions as a liaison between area-wide community health ventures and the department and oversees the department's CBPR efforts. The four neighborhood coordinators provide an ongoing presence in each neighborhood and maintain relationships with residents, leaders, agency representatives, and health care professionals. One resident-driven solution to promote access to health care in each neighborhood involved the creation of a community health worker (CHW) program which was instituted in 2004 (Zandee, Bossenbroek, Friesen, Blech \& Engbers, 2010; Zandee, Bossenbroek, Slager \& Gordon, 2013). The CHWs pair with nursing 
students to promote health, enhance access to care, and play a key role in the department's CBPR projects.

Given the mission-consistent nature of the department's CBPR work, the college provides financial support for several elements of the CBPR endeavor. The CPC and the neighborhood coordinator positions constitute a component of faculty workload and thus the college salary line item supports these roles. In addition, the college incorporates the costs associated with generating strategic health plans into an institutional research line item. After an initial three years of external grant funding, the departmental budget subsumed the $\mathrm{CHW}$ program. Finally, the departmental budget provides each neighborhood coordinator with a small sum designed to meet immediate community needs (i.e. health fairs) and maintain an ongoing community presence (i.e. rent for a community site of operation). This institutional support is foundational to the departmental CBPR work and yet the challenges related to sustainability of these items in the operating budget of a small, non-research intensive, tuition driven institution are significant. For example, the non-teaching credit in the faculty workload for the CPC and the neighborhood coordinators makes the department appear less efficient relative to student-faculty ratio targets. In response, the institution is presently seeking to identify two or three mission consistent, interdisciplinary research themes that might assist in prioritizing internal faculty scholarship support, engaging outside donors, and attracting students to the college. The departmental CBPR efforts may play a prominent role in one such theme.

The neighborhoods have listed unintended pregnancy and anxiety/depression as top health concerns. The corresponding CBPR projects will be described.

\section{Educating Women about Reproductive Health}

In 2008, the research team used a qualitative approach to explore unintended pregnancy-one of the concerns reported by residents in a partner neighborhood. The investigators conducted six focus group discussions (FGD) via racially homogeneous groupsCaucasian, African American, and Hispanic/Latinos in three of the departmental partner neighborhoods and a cohort of Native Americans. CHWs, who were residents and representative of the 
women from the partnering neighborhoods, participated in pretesting of the interview guide and recruiting participants. Forty-one women aged 18-44 years, who were pregnant or had experienced pregnancy within three years of the study, participated in the FGD. These women identified increasing knowledge of their bodies as an important means to address unintended pregnancy and to promote early recognition of pregnancy (Ayoola \& Zandee, 2013). For these women, knowing their bodies entailed knowledge of the menstrual cycle, when ovulation occurs, high risk pregnancy days, and the most likely time of menstrual flow. They specifically requested information on the reproductive system, the menstrual cycle, and the use of menstrual calendars. With the assistance of the $\mathrm{CHWs}$, the researchers disseminated the results of the FGD via small group community meetings and the community advisory group.

During the dissemination meetings, the research team also encouraged the women to suggest the next phase of the study. Specifically, the investigators asked the women to share their thoughts/concerns about using an ovulation test kit, monitoring cervical mucus, and completing a menstrual calendar and temperature graph. They solicited the women's suggestions on what to include in the intervention package. When asked about possible locations for the intervention, the women expressed a preference for home visits. To ensure that the "Knowing your Body" intervention was culturally sensitive, women were asked to identify things that they would deem to be culturally inappropriate in the content/activities. Similarly, the $\mathrm{CHWs}$ reviewed the project materials to ensure cultural appropriateness for the various racial/ethnic groups. The final design of the "Knowing your Body" intervention was based on the suggestions and input of the women in the neighborhoods, the CHWs, and the community advisory group.

The research team conducted the "Knowing your Body" pilot study in 2010. Twenty-two women aged $18-39$ years participated in the study designed to determine the feasibility of an intervention to promote women's knowledge of their bodies and to enhance their pregnancy planning ability. The intervention package contained: six ovulation test kits, a two-month menstrual log sheet/calendar, and educational brochures on female reproductive anatomy, hormones, menstrual cycle, birth control, body temperature changes,

Western Journal of Nursing Research, Vol 37, No. 10 (October 2015): pg. 1323-1339. DOI. This article is @ SAGE Publications and permission has been granted for this version to appear in e-Publications@Marquette. SAGE Publications does not grant permission for this article to be further copied/distributed or hosted elsewhere without the express permission from SAGE Publications. 
characteristics of cervical mucus, and adapting to pregnancy during the first trimester (Ayoola, Zandee, Slager, \& Feenstra, 2011). The study enhanced the CCDON community-based nursing curriculum. Sixty senior nursing students were trained to use educational brochures, conduct surveys, and implement the intervention during their public health practicum. Each woman in the study received three home visits. During the first visit, the women took a 20-minute baseline survey administered by nursing student/CHW teams. Two weeks later, the team conducted another one-hour home visit. During this visit, the women repeated the same survey (in order to ascertain a test-retest reliability) and received a "Knowing your Body" kit. Four to six weeks after the second visit, the nursing student/CHW team administered a post-intervention survey to evaluate the effectiveness of the intervention. The results of the pilot study were presented to the partner communities, the community advisory board, and at local, national, and international nursing conferences (Ayoola, Slager, Zandee, \& Feenstra, 2012; Ayoola et al., 2011; Ayoola, Zandee, \& Brewer, 2009). The pilot/feasibility study was successful and thus the research team designed a larger study to reach more women in the partnering neighborhoods.

The first wave of the preconception reproductive knowledge promotion (PREKNOP) intervention, commonly called the Women's Health Promotion Program in the neighborhoods, was initiated in September 2012 with a Robert Wood Johnson Foundation (RWJF) Nurse Faculty Scholar (NFS) Award. PREKNOP is a randomized, controlled trial among low-income mostly ethnic minority women living in three of the partnering, urban, underserved neighborhoods. Teams of nursing students and CHWs are administering the 12-month intervention and surveys in face-to-face interviews. The various stages of this project were funded both internally from Calvin College departmental, divisional, and college monies as well as externally from the RWJF NFS grant. The internal funding supported the CHWs, undergraduate research assistants, course releases for the primary investigator, and supplies.

One of the strengths of this project is that it is rooted in a residents' identified problem as well as their proffered solutions. The women received the project well, felt they learned important information, wished to teach their daughters this content, and desired 
group sessions with their friends on the reproductive topics taught in the program. A limitation inherent in a randomized controlled trial is the possibility that women in the intervention group share the information with women in the control group. Thus, we ensured that only one woman in a household participated in the program. A second limitation is the time intensive nature of the project-requiring nursing students and CHWs to conduct an average one-hour face-to-face home visit with each woman on a monthly basis for six months. The research team plans to analyze the month at which women demonstrated the highest knowledge scores to identify the optimal number of visits needed for understanding the intervention content and the need for "booster doses". A potential barrier lies in recruiting ethnic minority women into the program. Hence, the project team conducted door-todoor and general neighborhood recruitment in collaboration with the CHWs who are residents of the neighborhoods and of the same ethnic/racial group as the potential participants. The women listened and received project recruitment fliers with greater enthusiasm when delivered by the CHWs.

\section{Piloting an Anxiety/Depression Intervention for Women}

The 2009-2011 nursing department neighborhood surveys clearly verified the previously identified community concerns relative to anxiety/depression. Participants were asked if, in the past 30 days, they had struggled with the following some, most, or all of the time: (a)"Feeling so sad nothing could cheer you up" (30\%, 26\%, and $18 \%$ in the Hispanic, Black, and White neighborhoods respectivelycompared to $12 \%$ in the 2008 Centers for Disease Control and Prevention National Health Interview Survey[NHIS]); (b) "Nervousness" (26\%, 27\%, and 34\% in the Hispanic, Black, and White neighborhoods respectively-compared to $17 \%$ in the 2008 NHIS); and (c) "Hopelessness" (21\%, 14\%, and 13\% in the Hispanic, Black, and White neighborhoods respectively-compared to $8 \%$ in the 2008 NHIS). Given these results, the authors conducted focus groups in each partner neighborhood that explored seven domains relative to the experiences of ethnically diverse, impoverished women with anxiety and depression. These domains included conceptualization, effects, coping strategies, perceived causes of anxiety and depression,

Western Journal of Nursing Research, Vol 37, No. 10 (October 2015): pg. 1323-1339. DOI. This article is @ SAGE Publications and permission has been granted for this version to appear in e-Publications@Marquette. SAGE Publications does not grant permission for this article to be further copied/distributed or hosted elsewhere without the express permission from SAGE Publications. 
current/desired community mental health resources, and barriers to help seeking (Doornbos, Zandee, \& DeGroot, 2012; Doornbos, Zandee, DeGroot, \& Warpinski, 2013; Doornbos, Zandee, DeGroot, \& De Maagd-Rodriguez, 2013). The CHWs assisted with recruitment of participants, creation of a semi-structured interview guide, facilitation of the Spanish focus group, transcription, and review of themes. The research team returned to the partner neighborhoods with the results to determine next steps. Across the communities, the women wished to meet in small groups for purposes of support and education around depression and anxiety. They identified content they wished to learn about, preferred locations, desired leadership structure, and potential barriers (Doornbos et al., 2013).

These results led to the creation of a pilot intervention entitled Women Supporting Women (WSW). WSW is a study that offers supportive/educative groups at four neighborhood sites that the women find convenient and comfortable-a church, neighborhood center, homeless shelter, and religiously affiliated emergency food center. The CPC and the CHWs facilitate recruitment for the study, which has even resulted in a waiting list in one of the communities. The research team addresses barriers to participation identified by the women during the focus group phase via the provision of transportation and childcare. The goal of the study is to decrease symptoms and increase knowledge for self-care relative to anxiety/depression. The intervention consists of six, 90-minute sessions of a supportive/educative group including the elements of connecting, education, and support. The educational component covers the symptoms, causes, and treatment options for anxiety/depression as well as cognitive/behavioral strategies to prevent or cope with these health issues. The supportive component occurs around crafts and refreshments where the women have the opportunity to form relationships. Facilitated by $\mathrm{CHWs}$, taught by undergraduate nursing students, and supervised by faculty members, the research team incorporates the group leadership suggestions of the women in each of the partner neighborhoods. The CHWs are involved in the planning of each supportive/educational session including the identification of culturally sensitive language, teaching/learning strategies, crafts, and refreshments. Data is collected pre-intervention, post-intervention, and at six months. 
As with all research, strengths, limitations, and barriers are inherent in this study. As to strengths, preliminary results from the WSW pilot study indicate that the women are highly satisfied with the intervention, the adequacy of knowledge for self-care for depression and anxiety have increased, and anxiety symptoms have decreased from pre-test to six-month follow up. Depression scores, however, remain unchanged at the immediate post-test and six-month follow up point (Doornbos, Zandee, DeGroot \& Bossenbroek, 2013). The potential weakness in the scientific method relates to intervention fidelity issues given the delivery of the educational intervention by undergraduate students to ethnically diverse groups. The research team addresses this via thorough initial orientation and ongoing consultation prior to each group session. Other barriers relate to the vulnerability of this population and resulting difficulties keeping women in the study. These women have fragile lives that may entail eviction, geographic relocation, homelessness, unemployment, transportation issues, inconsistent telephone access, and childcare issues. The research team attempts to address these barriers via obtaining alternative phone numbers in case numbers change or minutes run out, making 2-3 reminder calls/texts prior to each group session, offering transportation for each session, and providing childcare during the sessions. In addition, early feedback from the women and the $\mathrm{CHW}$ in the Spanish-speaking neighborhood outlined the difficulties inherent in discussing sensitive mental health topics in English and thus all sessions in this neighborhood are now entirely in Spanish.

Funding for WSW has been internal as well as external. While the $\mathrm{CPC}$ and the $\mathrm{CHWs}$ were supported as previously described, the research team obtained departmental and college funding to support the activities of the primary investigator and the undergraduate research assistants. This support came in the form of a sabbatical leave and several academic semester course releases as well as wages for the research assistants. In addition, the primary investigator worked in tandem with the college's Development Office to secure external funding from the Perrigo Company Foundation for specific expenses such as transportation, printing, room rental, supplies, food, and wages for childcare providers and the undergraduate research assistants. 
NOT THE PUBLISHED VERSION; this is the author's final, peer-reviewed manuscript. The published version may be accessed by following the link in the citation at the bottom of the page.

\section{Conclusion}

The need to conduct research with communities is increasingly apparent. While there are several perceived barriers to such a pursuit, CBPR represents an approach to mitigating these obstacles. Three CBPR case studies, conducted in non-research intensive nursing programs, demonstrated an emphasis on community strengths, collaboration, equitable involvement, empowerment, mutual benefit, dissemination of findings, and long-term commitment (Israel et al., 1998; Israel et al., 2001; Israel et al., 2008). These examples illustrate how CBPR can be effectively employed in the pursuit of community driven programs of research that are responding in a culturally sensitive manner to identified needs of underserved communities. The cases highlight community residents identifying, prioritizing, and addressing complex issues such as obesity, unintended pregnancy, and depression/anxiety in tandem with nurse researchers in order to create relevant and efficacious interventions. While the health challenges facing local communities are often documented on the regional and national level, local interpretations and context specific interventions are key to relevant solutions. The community residents functioned as experts on the multifaceted array of socioeconomic, cultural, and community factors that must be considered in studies on these complex topics-without which the interventions would have been poorly received by the intended recipients and unsustainable. Preliminary results of these studies with vulnerable women suggest satisfaction and positive outcomes.

CBPR, as described in the three case studies, is applicable to other non-research intensive academic environments. The three case studies demonstrate "small studies designed to solve local problems"a desired trend in nursing research (Polit \& Beck, 2014). Rhodes et al. (2012) suggest that successful interventions need to respond to local community priorities while building capacity for communities to act on their own behalf. Such local research, reflecting specific community needs, has significant potential to produce effective local policy and practice (Mitchell \& Schmidt, 2011). Non-research intensive schools have access to their local communities, can forge partnerships characterized by collaboration and power sharing, and can address research priorities gradually in the context of long-term relationships

Western Journal of Nursing Research, Vol 37, No. 10 (October 2015): pg. 1323-1339. DOI. This article is C SAGE Publications and permission has been granted for this version to appear in e-Publications@Marquette. SAGE Publications does not grant permission for this article to be further copied/distributed or hosted elsewhere without the express permission from SAGE Publications. 
as resources and capacity allow. As such, schools of nursing with limited research funding can engage in narrow scope research that is meaningful to and perhaps supported by their institutions, potentially of interest to local funding agencies, and ultimately beneficial to their local communities.

The National Institute of Nursing Research's (NINR) strategic plan identified research priorities to focus the efforts of our discipline over the next quarter century (NINR, 2011). One of those priorities is to expand the science around health promotion and disease prevention:

Multilevel, community-based, participatory research will further an understanding of the barriers and incentives that influence behavioral change. The continued development of culturally appropriate, evidence-based interventions for use with at-risk and underserved populations will contribute to the promotion of health equity and the elimination of health disparities (NINR, 2011, p. 11).

These case examples illustrate studies that are developing interventions around obesity, reproductive health, and mental health for these explicit purposes. While the temptation is to assume that such scholarship can only occur at large, well-funded, researchintensive universities, that is not the case. The reality is that nonresearch intensive environments, with limited research funding and predominately-undergraduate populations, can make significant contributions to furthering the science and research priorities of our discipline.

\section{Acknowledgments}

Note: The Maintaining Healthy Body Weight among Underserved AfricanAmerican Women was funded by: Healthier Wisconsin Partnership Program, Project title: Promoting Healthy Body Weight among African American Women through a Community Participatory Model, E. Burns, P.I. \& Grant 8UL1TR000055; National Center for Research Resources and the National Center for Advancing Translational Sciences, National Institutes of Health, through Grant Number 8UL1TR000055. 
NOT THE PUBLISHED VERSION; this is the author's final, peer-reviewed manuscript. The published version may be

accessed by following the link in the citation at the bottom of the page.

\section{About the Authors}

Mary Molewyk Doornbos, Nursing, Calvin College, Department of Nursing, 1734 Knollcrest Circle SE, Grand Rapids, MI 49546-4403, Office: 616526-6268, Fax: 616-526-6501, Email: ude.nivlac@rood.

Adejoke Ayoola, Robert Wood Johnson Foundation Nurse Faculty Scholar, Associate Professor of Nursing, Calvin College, Department of Nursing, 1734 Knollcrest Circle SE, Grand Rapids, MI 49546-4403, Office: 616526-6059, Email: ude.nivlac@3abA.

Robert Topp, Research, Marquette University, College of Nursing, Milwaukee, Wisconsin, Office: 414-288-3811, Email: ude.etteuqram@ppot.treboR.

Gail Landheer Zandee, Nursing, Calvin College, Department of Nursing, 1734 Knollcrest Circle SE, Grand Rapids, MI 49546-4403, Office: 616-5266814, Email: ude.nivlac@eednazg..

\section{References}

Anachebe NF. Racial and ethnic disparities in infant and maternal mortality. Ethnicity \& Disease. 2006;16(2 Suppl 3) S3-71-6.

Ayoola $A B$, Slager $D$, Zandee $G L$, Feenstra $C$. A pilot study on promoting lowincome minority women's self-efficacy of their knowledge of the body. 2012 Retrieved from http://www.nursinglibrary.org/vhl/handle/10755/201916?mode=full.

Ayoola AB, Zandee GL. Low-income women's recommendations for promoting early pregnancy recognition. Journal of Midwifery \& Women's Health. 2013;58(4):416-422.

Ayoola $A B$, Zandee $G L$, Brewer JR. Exploring the pregnancy recognition process using group interviews. 2009 Retrieved from http://www.nursinglibrary.org/vhl/handle/10755/148591.

Ayoola AB, Zandee GL, Slager D, Feenstra C. Preconception monitoring of women's ovulation time and other menstrual changes: A pilot study. 2011 Retrieved from http://www.nursinglibrary.org/vhl/handle/10755/156349?mode=full.

Campbell KS, Zhang J, Nicoloff P, Betlej L, Goodwin G, Topp R. Prevalence of obesity and select clinical characteristics associated with obesity among African American women in nurse-managed clinics. Paper presented at the Sigma Theta Tau 42nd Biennial Convention; Indianapolis, IN, USA. 2013. Nov,

Centers for Disease Control and Prevention. Summary health statistics for U.S. adults: National health interview survey, 2008. 2008 Retrieved from http://www.cdc.gov/nchs/data/series/sr_10/sr10_242.pdf.

Center for Disease Control and Prevention. CDC - Groups especially affected by diabetes - Diabetes \& Me - Diabetes DDT. 2014 Retrieved from http://www.cdc.gov/diabetes/consumer/groups.htm.

Western Journal of Nursing Research, Vol 37, No. 10 (October 2015): pg. 1323-1339. DOI. This article is @ SAGE Publications and permission has been granted for this version to appear in e-Publications@Marquette. SAGE Publications does not grant permission for this article to be further copied/distributed or hosted elsewhere without the express permission from SAGE Publications. 
NOT THE PUBLISHED VERSION; this is the author's final, peer-reviewed manuscript. The published version may be accessed by following the link in the citation at the bottom of the page.

Doornbos MM, Zandee GL, DeGroot J, De Maagd-Rodriguez M. Using community-based participatory research to explore social determinants of women's mental health and barriers to help- seeking in three urban, ethnically diverse, impoverished, and underserved communities. Archives of Psychiatric Nursing. 2013;27(6):278-284.

Doornbos MM, Zandee GL, DeGroot J, Warpinski M. Desired mental health resources for ethnically diverse, impoverished women struggling with anxiety and depression. Qualitative Health Research. 2013;23(1):7892.

Doornbos MM, Zandee GL, DeGroot J, Bossenbroek D. Supportive/educative groups as a culturally sensitive intervention for women's anxiety and depression in three urban, ethnically diverse, impoverished, and underserved communities. Paper presented at the Midwest Nursing Research Society (MNRS) 37th Annual Research Conference; Chicago, Illinois. 2013. Mar,

Doornbos MM, Zandee GL, DeGroot J. Clinging to any bit of joy: Urban, ethnically diverse, impoverished women's descriptions of anxiety and depression. Archives of Psychiatric Nursing. 2012;26(6):437-447.

Feenstra C, Gordon B, Hansen D, Zandee G. Managing community and neighborhood partnerships in a community-based nursing curriculum. Journal of Professional Nursing. 2006;22(4):236-241.

Finer LB, Henshaw SK. Disparities in rates of unintended pregnancy in the United States, 1994 and 2001. Perspectives on Sexual and Reproductive Health. 2006;38(2):90-96.

Finer LB, Zolna MR. Unintended pregnancy in the United States: Incidence and disparities, 2006. Contraception. 2011;84(5):478-485.

Ford ME, Siminoff LA, Pickelsimer E, Mainous AG, Smith DW, Diaz VA, Soderstrom LH, Jefferson MS, Tilley BC. Unequal burden of disease, unequal participation in clinical trials: Solutions from African American and Latino community members. Health and Social Work. 2013;38(1):29-38.

George S, Duran N, Norris K. A systematic review of barriers and facilitators to minority research participation among African Americans, Latinos, Asian Americans, and Pacific Islanders. American Journal of Public Health. 2014;104(2):16-31.

González HM, Tarraf W, Whitfield KE, Vega WA. The epidemiology of major depression and ethnicity in the United States. Journal of Psychiatric Research. 2010;44(15):1043-1051.

Hauck FR, Tanabe KO, Moon RY. Racial and ethnic disparities in infant mortality. Seminars in Perinatology. 2011;35(4):209-220.

Israel BA, Schulz AJ, Parker EA, Becker AB. Review of community-based research: Assessing partnership approaches to improve public health. Annual Review of Public Health. 1998;19:173-202.

Western Journal of Nursing Research, Vol 37, No. 10 (October 2015): pg. 1323-1339. DOI. This article is @ SAGE Publications and permission has been granted for this version to appear in e-Publications@Marquette. SAGE Publications does not grant permission for this article to be further copied/distributed or hosted elsewhere without the express permission from SAGE Publications. 
NOT THE PUBLISHED VERSION; this is the author's final, peer-reviewed manuscript. The published version may be accessed by following the link in the citation at the bottom of the page.

Israel BA, Schulz AJ, Parker EA, Becker AB. Community based participatory research: Policy recommendations for promoting a partnership approach in health research. Education for Health. 2001;14(2):182197.

Israel BA, Schulz AJ, Parker EA, Becker AB, Allen A, Guzman JR. Critical issues in developing and following CBPR Principles. In: Minkler M, Wallerstein $\mathrm{N}$, editors. Community-based participatory research for health: From process to outcomes. 2nd. San Francisco, CA: JosseyBass; 2008. pp. 47-66.

Kneipp SM, Lutz BJ, Means D. Reasons for enrollment, the informed consent process, and trust among low-income women participating in a community-based participatory research study. Public Health Nursing. 2009;26(4):362-369.

Mathews TJ, MacDorman MF. Infant mortality statistics from the 2009 period linked birth/infant death data set. National Vital Statistics Reports. From the Centers for Disease Control and Prevention, National Center for Health Statistics, National Vital Statistics System. 2013;61(8):127.

McGuire TG, Miranda J. New evidence regarding racial and ethnic disparities in mental health: Policy implications. Health Affairs. 2008;27(2):393403.

Minkler M. Community-based participatory research for health: From process to outcomes. Hoboken, NJ: John Wiley \& Sons; 2011.

Mitchell J, Schmidt G. The importance of local research for policy and practice: A rural Canadian study. Journal of Social Work Practice in Addictions. $2011 ; 11(2): 150-162$.

National Institute of Nursing Research. Bringing science to life: NINR strategic plan. 2011 Retrieved from https://www.ninr.nih.gov/sites/www.ninr.nih.gov/files/ninr-strategicplan-2011.pdf.

O'Brien MJ, Whitaker RC. The role of community based participatory research to inform local health policy. Journal of General Internal Medicine. 2011;26(12):1498-1501.

Office of Minority Health \& Health Disparities (OMHD) Eliminating racial and ethnic disparities. 2009 Retrieved from http://www.cdc.gov/omhd/about/disparities.htm.

Polit DF, Beck CT. Essentials of nursing research: Appraising evidence for nursing practice. Philadelphia, PA: Wolters Kluwer/Lippincott Williams \& Wilkins; 2014.

Rhodes SD, Kelley C, Siman F, Cashman R, Alonzo J, McGuire J, Reboussin B. Using community-based participatory research (CBPR) to develop a community-level HIV prevention intervention for Latinas: A local

Western Journal of Nursing Research, Vol 37, No. 10 (October 2015): pg. 1323-1339. DOI. This article is @ SAGE Publications and permission has been granted for this version to appear in e-Publications@Marquette. SAGE Publications does not grant permission for this article to be further copied/distributed or hosted elsewhere without the express permission from SAGE Publications. 
NOT THE PUBLISHED VERSION; this is the author's final, peer-reviewed manuscript. The published version may be accessed by following the link in the citation at the bottom of the page.

response to a global challenge. Women's Health Issues. 2012;22(3):e293-e301.

Rugkasa J, Canvin K. Researching mental health in minority ethnic communities: Reflections on recruitment. Qualitative Health Research. 2011;21(1):132-143.

The Henry J. Kaiser Family Foundation. Putting women's health care disparities on the map: Examining racial and ethnic disparities at the state level. 2009 Retrieved from http://kfforg/disparitiespolicy/report/putting-womens-health-care-disparities-on-the/map.

Tucker MJ, Berg CJ, Callaghan WM, Hsia J. The Black-White disparity in pregnancy-related mortality from 5 conditions: Differences in prevalence and case-fatality rates. American Journal of Public Health. 2007;97(2):247-251.

Wallerstein N, Duran B. Community-based participatory research contributions to intervention research: The intersection of science and practice to improve health equity. American Journal of Public Health. 2010;100(S1):S40-S46.

Zandee GL, Bossenbroek D, Friesen M, Blech K, Engers R. Effectiveness of community health worker/nursing student teams as a strategy for public health nursing education. Public Health Nursing. 2010;27(3):277-284.

Zandee G. Mapping a strategic plan for health: Community-based participatory research with underserved, low-income, urban neighborhoods. Journal of Higher Education Outreach and Engagement. 2012;16(3):95.

Zandee GL, Bossenbroek D, Slager D, Gordon B. Teams of community health workers and nursing students effect health promotion of underserved urban neighborhoods. Public Health Nursing. 2013;30(5):439-447.

Western Journal of Nursing Research, Vol 37, No. 10 (October 2015): pg. 1323-1339. DOI. This article is @ SAGE Publications and permission has been granted for this version to appear in e-Publications@Marquette. SAGE Publications does not grant permission for this article to be further copied/distributed or hosted elsewhere without the express permission from SAGE Publications. 